\title{
Clinical analysis of vulvar carcinoma
}

\author{
Raghvendra Thakur ${ }^{1}$, Nijamudin ${ }^{2}$, Zheng Xue hua ${ }^{3}$, Zhang Mengli', Wu yan Jun ${ }^{1}$, Tian Yuan ${ }^{1}$ and Zheng Guiying ${ }^{1 *}$ \\ *Correspondence: drzhengguiying@gmail.com \\ 'Department of Obstetrics and Gynecology, Second Hospital of Jilin University, Norman Bethune College of \\ Medicine, Ziqiang Street, Changchun, P.R.China. \\ 2Department of emergency medicine, Second Hospital of Jilin University, Norman Bethune College of Medicine, \\ Ziqiang Street, Changchun, P.R.China. \\ ${ }^{3}$ Department of obstetrics and gynecology, Maternity and children hospital, Jilin Province, Liaoyuan city, \\ Jilin province, P.R.China.
}

\begin{abstract}
Objective: The purpose of this study is to understand the incidence, related factors, and the prognosis factors in order to avoid risk, proper method of diagnosis and treatment and reduce complications and provide the basis.

Methods: 85 Vulvar cancer (VC) patients treated in our hospital from 2002.10 to 2012.10 were collected and analyzed by retrospective comparative methods. SPSS19.0 application software was used for the statistical analysis. The clinical data are analyzed by chi-square and $\mathrm{F}$ test statistic methods. $P<0.05$ was a significant difference between the judgment standard.

Results: During 10 years, we treated 3391 cases of the primary malignant tumors including 85 VC cases; VC was $2.89 \%$ (85/3391). The age was between $24 \sim 88$ years old, mean was $57.09 \pm 12.93$ yrs. old, variable age $(F=6.013, P=0.016<0.05)$. VC had seen more in rural than urban patients. By statistical analysis, region distribution in these two groups was remarkably different $=4.16$, $P=0.045<0.05$, but the urban proportion of patients in different years has no difference $(\chi 2=0.080, P=0.777)$.

Conclusion: The number of cases increased progressively in young age. VC patients were more in rural area than urban. High-risk groups Suggested doing regular physical exam. For long-term genital itching, genital tumor, genital ulcers, and other symptoms, should be alert to the possibility of VC. Preoperative diagnosis should be Colposcopic, biopsy in order to improve the accuracy of earlier diagnosis. Postoperative common complications are wound infection. Follow-up rate is low; It is difficult to say statistically survival rate is 5 years.
\end{abstract}

Keywords: Vulvar carcinoma, sentinel lymph node, risk factor, clinical manifestation, chemotherapy

\section{Introduction}

Vulvar cancer (VC) is about $3 \%$ to $5 \%$ of all primary gynecological malignancies, annual incidence rate is about 2 to $3 / 10$ [1]. The vast majority of vulvar lesion occurs in the genital skin surface with early symptoms like vulvar itching, pain, small excrescence. Early diagnosis rate of Vulvar cancer are increasing nowadays. Vulvar cells similar to a cervical cytology brush (Rovers Medical Devices BV) are expected to become an important tool in the prevention and early diagnosis of vulvar cancer. In addition, CT examination with high specificity in vulvar cancer lymph node metastasis, improve the accuracy of the preoperative diagnosis. The range of options such as surgery, selective sentinel node and inguinal lymph node dissection, therapeutic applications, Chemotherapy or a combination of chemotherapy treatment etc is available. VC originates from 2 different etiologies. A class of histological features of well differentiated keratinizing squamous cell carcinoma: occurs in women over the age of 50 and often concomitant vulva non-neoplastic epithelial lesions (VNED) such as chronic inflammation, genital lichen sclerosis. This types of lesions in the HPV-DNA detection rate is low $(<15 \%)$. Histological features mostly as epidermal carcinoma (Bowen's carcinoma, warty carcinoma), are common in young women. Epidemiological this type of VC risk factors includes smoking, sexually transmitted diseases (STD), and immune suppression. Most study shows that this type of lesions in the
HPV-DNA, especially HPV 16 , \& 18 accounts for $40 \%$ to $51 \%$, often with concomitant cervical lesions [2]. Lymph node metastasis has greater impact on the prognosis of VC. FIGO Committee Gynecologic Oncology Group revised the staging of vulvar cancer lymph node involvement [3]. In the new staging, no lymph node metastasis \& invasion of adjacent organs cases regardless of the size of the lesion- divided into phase I. Only invasion of adjacent organs, but no lymph node metastasis were divided into Phase II; lymph node metastasis were divided into Phase III with subdivision of lymph node involvement. Surgery such as genital radical resection + inguinal lymph node resection for the vulvar traditional standard technique, this surgical inguinal lymph node dissection routinely cut off the great saphenous vein stripping fascia lata. This technique has large range of damage, and delayed healing, often appear as a lymphatic retention cyst, lower extremity edema, incontinence, sexual dysfunction, and seriously affecting the quality of life of patients. About $90 \%$ of vulvar squamous cell carcinoma, adenocarcinoma, squamous cell carcinoma of all anti-cancer drug sensitivity is lower; the chemo treatment of VC often can be used as a vulvar advanced cancer or recurrent VC. Chemotherapy drugs are mitomycin C (MMC), bleomycin (BLM), cisplatin (DDP), methotrexate (MIX), and cyclohexyl nitrosourea (CCNU). The implementation of concurrent radiotherapy and chemotherapy can achieve better efficacy. 5 - Fluorouracil 
Thakur et al. Gynecology 2013,

(5-FU) or 5-FU + cisplatin combination chemotherapy is the most commonly used chemotherapy regimens. Hamp [4] identified HPV vaccine is feasible to reduce the reproductive tract disease. Since Merck Gardasil cervical cancer preventive vaccines listed, the vaccine in the prevention of its related vulvar and vaginal intraepithelial neoplasia. The vaccine is beneficial for all young women and even in existing HPV infection. In addition, the treatment of VC can also consider the use of laser-assisted and immunomodulatory drugs combined with chemotherapy treatment achieved satisfactory results. The treatment of VC, surgeons and scholars considered the main problem is how to improve the survival rate, at the same time minimize postoperative complications, improve quality of life \& prevention of recurrence. The present study is more focused on the treatment options, but its advantages and feasibility still a large number of evidence-based medicine support. With the sentinel lymph node biopsy technique of continuous research and improvement and development of the genital reconstruction techniques, we have reason to believe it will find the best treatment of VC, so that patients get the maximum therapeutic benefit with minimal trauma.

\section{Materials and methods}

With the prior approval from the institution that is a second clinical hospital of Jilin University, Changchun, China, data was collected from 2002-10 to 2012-10; all of the patients admitted with VC. Data was collected from hospital medical records and all patients were confirmed by clinical, pathological diagnosis.

\section{Case inclusion criteria}

Diagnosis was confirmed through pathological consultation. All patients (pt.) were newly diagnosed, Pt. with complete clinical and pathological data were collected.

\section{Case exclusion criteria}

A high degree of suspicion, without pathological confirmation; Secondary surgery or postoperative adjuvant therapy outside our hospital after primary treatment; and incomplete clinical and pathological data.

\section{Methods}

Grouping method: 85 cases of VC patient were grouped according to different criteria. According to admission time 5 groups ( $A, B, C, D, E)$ were made, each group of 2 years i.e., Group A (2002.10-2004.09), group B (2004.10-2006.09), group C (2006.10-2008.09), group D (2008.09-2010.09), and group E (2010.09-2012.09). Surgical methods are divided into: Local excision of vulvar lesions; Modified radical vulvectomy/radical local excision; Radical vulvectomy (extensive genital radical surgery) which is in divided into: a) genital lesions, b) groin lymph node. According to the pathological type: vulvar squamous cell carcinoma and squamous cell carcinoma (malignant melanoma, Paget's disease, basal cell carcinoma,Verrucous carcinoma, bartholin adenocarcinoma and sarcoma). Lymph node metastasis into the lymph node positive group and negative group; According to the histological grade is divided into: well differentiated (G1), moderately differentiated (G2) and poorly differentiated (G3) group; Menopause situation is divided into the postmenopausal group and premenopausal group; Classification of weight according to the body mass index (BMI), BMI24 as overweight/obese group.

\section{Clinical and pathological data collection \\ General analysis of the patient}

Admission time, Age, Weight, Menarche and age at menopause, Symptoms, Medical history, Co-morbidities, Preoperative laboratory examination, Clinical stage, histology and Pathological findings of the surgical specimens, adverse reaction after chemotherapy, and Comprehensive treatment analysis.

\section{Staging criteria \\ According to 2009 FIGO VC staging system [3].}

\section{Statistical analysis}

The database was established on excel analyzed in SPSS19. Statistical methods $\times 2$ test, $\mathrm{P}<0.05$ database was established on excel and analyzed in SPSS version 19 , statically method $\mathrm{X}^{2}$ test $\mathrm{P}<0.05$ was used to determine significant differences.

\section{Results}

In group $A$ the incidence of number cases were 8 , (5 rural areas) accounting for $62.50 \%$, in group B 10 cases (rural residents 6) accounted for $60 \%$, group $C 11$ cases (rural residents 6) accounting for $54.55 \%, 17$ cases in group D (10 in rural areas) accounting for $58.82 \%, 39$ cases in group $E$ (rural area 22) accounting for $56.41 \%$. The number of patients hospitalized increased year by year. There is significant incidence of urban and rural areas of $\mathrm{VC}(\mathrm{F}=4.16, \mathrm{P}=0.045<0.05)$ rural areas are more prone to VC (Figure 1).

\section{Age distribution}

Age ranged from 24 to 88 years old, average was $57.09 \pm 12.93$ years, median 58 years and a minimum of $\leq 40 \geq 70$. Statistically significance $(F=6.013, P=0.016<0.05)$ (Table 1, Figure 2).

\section{History}

Menarche of patient was between 11 to 20 years old, mean 16 year old. Total menopausal patient 50 accounting for $58.82 \%$. The higher incidence of VC was seen with postmenopausal case, 7 out of 8 cases accounting for $87.5 \%$ in year 2002 to 2004 and 20 out of 39 cases accounting for $51.28 \%$ in 2010 to 2012. Statistical analysis $(P=0.4888>0.05)$ (Table 2).

\section{Complications}

According to the body mass index, $\mathrm{BMI}>24$ classified overweight, obese group (Table 3). It shows VC patient with 

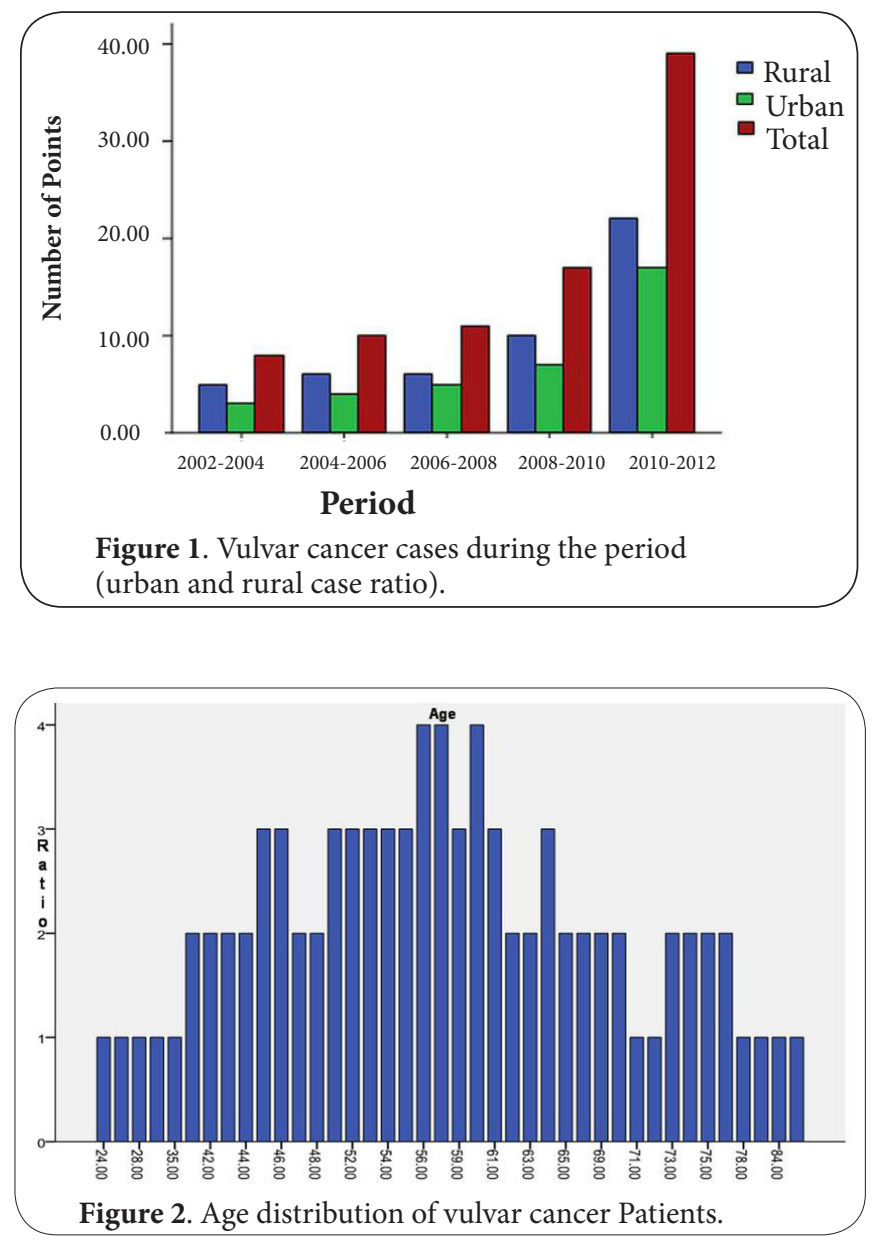

Table 1. Patients with treatment time and age distribution data (years).

\begin{tabular}{ccccccc}
\hline Groups & Mean age & No. of case & $\begin{array}{c}\text { Standard } \\
\text { deviation }\end{array}$ & $\begin{array}{c}\text { Median } \\
\text { age }\end{array}$ & $\begin{array}{c}\mathrm{F} \\
\text { value }\end{array}$ & $\begin{array}{c}\text { P } \\
\text { values }\end{array}$ \\
\hline $2002-2004$ & 63.3750 & 8 & 10.37769 & 62.5000 & $\mathrm{~F}=6.013$ \\
$2004-2006$ & 62.6000 & 10 & 11.25660 & 65.0000 & $\mathrm{P}=0.016$ \\
$2006-2008$ & 59.4545 & 11 & 10.06344 & 56.0000 & \\
$2008-2010$ & 55.7059 & 17 & 10.39690 & 56.0000 & \\
$2010-2012$ & 54.3333 & 39 & 14.85603 & 54.0000 & \\
Total & 57.0941 & 85 & 12.92526 & 58.0000 & \\
\hline
\end{tabular}

vulvar intraepithelial neoplasia were $29.41 \%$, suggesting that the neoplastic lesions have developed from vulvar intraepithelial lesion. Overweight/obese patients accounted for $38.82 \%$, may be related to the incidence of VC. Univariate analysis of data results showed that: Malignancy associated with the incidence of $\mathrm{VC}$, statistical analysis $(\mathrm{P}=0.023<0.05)$, Operative history and cancer of vulva has some correlation. In this study preoperative HPV testing were 31 (36.47\%) and patient with the positive rate of HPV infection were $12.9 \%$. Ratio is low and the number of samples may be less relevant.

\section{Clinical manifestations}

The main symptoms of patient attending were genital mass, genital or vulvar pruritis, genital ulceration, vulvar pain; of which genital tumor and genital itching more common, accounting for $70.59 \%$ (60/85) \& 56.47\% (48/85) (Table 4).

\section{History time}

Patients had obvious symptoms before treatment. The time difference of patient visit was a minimum of 10 days, maximum up to 20 weeks. Peak was for 2 months to 1 year (Table 5).

\section{Lesion location and size}

Lesions were distributed in the labia majora, labia minora, perineum, clitoris, urethra, and in patient with advanced disease and it spread to the anal and vaginal wall. According to the location 62 cases i.e., $72.94 \%$ of cases accounted for the lateral side of labia, while 23 cases i.e., $27.06 \%$ accounted for medial or midline of clitoris and perineum. According to size it is divided into 3 groups that is $2 \mathrm{~cm}, 2 \mathrm{~cm}-5 \mathrm{~cm}$ and $\geq 5 \mathrm{~cm}$. patients with lesion size $<2 \mathrm{~cm}, 2-5 \mathrm{~cm},>5 \mathrm{~cm}$ were 16 (18.82), 59(69.41), 10(11.77) respectively ( Table 6).

\section{VC patient's diagnosis and reliability}

Out of 85 cases of VC patient, 78 underwent biopsy; and the rate was $91.76 \%$. 2 cases of biopsy made diagnosis of focal squamous mild to moderate atypical hyperplasia, postoperative pathological diagnosis was verrucous squamous cell carcinoma. 1 case of extra mammary pagets disease as well differentiated squamous cell carcinoma, Pathologically proven after operation. In 1 case, 1 st biopsy made a diagnosis of vulvar chronic inflammation while 2 nd biopsy made a diagnosis of well differentiated squamous cell carcinoma. The accuracy of pathological tissue differentiation on biopsy was $83.33 \%$ (60/72), 1 case underwent colposcopy, shows mosaic pattern outside the local vessels. The intraoperative diagnosis was medium to low differentiated vulvar squamous cell carcinoma. 20 patients underwent cervical VCE, operative pathology reports were well differentiated squamous cell carcinoma.

\section{CT and MRI}

From 85 patient 6 and 2 received CT and MRI respectively, and indicated vulvar cancer lesion. CT and MR imaging showed 8 cases of primary tumor, 3 cases located in the central and bilateral side, 2 cases only on the left side, and 3 cases only on right side. The incidence rate of localization was $100 \%(8 / 8)$. Diameter of the tumor was between $1-8 \mathrm{~cm}$. with maximum of $8 \mathrm{~cm}$ (mean $4 \mathrm{~cm}$.). The $\mathrm{CT}$ examination over estimates 2 cases, in 1 case CT showed the lesion size of $2.3 \mathrm{~cm}$ classified as IB stage, but postoperative pathologic examination of the tumor was $<2 \mathrm{~cm}$ and staged for IA. Similarly in another CT showed enlargement of lymph nodes and diagnosed as stage III; post operative pathology confirmed no lymph node metastasis, so the diagnosis was stage II. CT examination underestimates diagnosis in 1 case, it was IB rather than IA showed postoperative histopathological report. However 
Thakur et al. Gynecology 2013,

http://www.hoajonline.com/journals/pdf/2052-6210-1-5.pdf

doi: $10.7243 / 2052-6210-1-5$

Table 2. Patient's menopause status (\%).

\begin{tabular}{|c|c|c|c|c|c|c|c|c|c|c|c|c|}
\hline \multirow{2}{*}{ Menopause } & \multicolumn{2}{|c|}{$02-04 y r$} & \multicolumn{2}{|c|}{$04-06 y r$} & \multicolumn{2}{|c|}{$06-08 y r$} & \multicolumn{2}{|c|}{$08-10 \mathrm{yr}$} & \multicolumn{2}{|c|}{$10-12 \mathrm{yr}$} & \multicolumn{2}{|c|}{ total } \\
\hline & No. of cases & $\%$ & No. & $\%$ & No. & $\%$ & No. & $\%$ & No. & $\%$ & No. & $\%$ \\
\hline Postmenopausal & 7 & 87.5 & 6 & 60.0 & 7 & 63.64 & 11 & 64.71 & 19 & 48.72 & 50 & 58.82 \\
\hline Premenopausal & 1 & 12.5 & 4 & 40.0 & 4 & 36.36 & 6 & 35.29 & 20 & 51.28 & 35 & 41.18 \\
\hline Total & 8 & 100.0 & 10 & 100.0 & 11 & 100.0 & 17 & 100.0 & 39 & 100.0 & 85 & 100.0 \\
\hline
\end{tabular}

Table 3. Patients with complications (\%).

\begin{tabular}{ccccccccc}
\hline Risk factors & VNED & Genitals surgery & Malignancy & $\begin{array}{c}\text { Familial } \\
\text { malignant }\end{array}$ & $\begin{array}{c}\text { HPV } \\
\text { Infection* }\end{array}$ & Hypertension & Diabetes & obesity \\
\hline N & 25 & 23 & 19 & 2 & 4 & 10 & 13 & 33 \\
$\%$ & 29.41 & 27.06 & 22.35 & 2.35 & 12.9 & 11.76 & 15.29 & 38.82 \\
\hline
\end{tabular}

Note: * The preoperative HPV testing by a total of 31 (36.47\%) patients;

Table 4. Vulvar cancer clinical manifestations.

\begin{tabular}{lccccccccc}
\hline \multicolumn{2}{l}{ Genital tumor } & \multicolumn{2}{l}{ genital itching } & \multicolumn{2}{c}{ genital ulceration } & \multicolumn{2}{c}{ genital pain } & \multicolumn{2}{c}{ other $^{*}$} \\
\hline No. & $\%$ & No. & $\%$ & No. & $\%$ & No. & $\%$ & No. & $\%$ \\
60 & 70.59 & 48 & 56.47 & 34 & 40.0 & 30 & 35.29 & 22 & 25.88 \\
\hline
\end{tabular}

Table 5. History of present illness time distribution.

\begin{tabular}{|c|c|c|c|c|c|c|c|c|c|c|c|c|}
\hline \multirow{2}{*}{$\frac{\text { History Time }}{-}$} & \multicolumn{2}{|c|}{$\leq 2$ Month } & \multicolumn{2}{|c|}{2 Month to 1 year } & \multicolumn{2}{|c|}{1 to 3 years } & \multicolumn{2}{|c|}{4 to 6 years } & \multicolumn{2}{|c|}{7 to 10 years } & \multicolumn{2}{|c|}{$>10$ years } \\
\hline & No. & $\%$ & No. & $\%$ & No. & $\%$ & No. & $\%$ & No. & $\%$ & No. & $\%$ \\
\hline No. of cases & 8 & 9.41 & 40 & 47.06 & 14 & 16.47 & 9 & 10.59 & 8 & 9.41 & 6 & 7.06 \\
\hline
\end{tabular}

Table 6. Location and size of the lesion.

\begin{tabular}{c|ccccc}
\hline & \multicolumn{2}{|c}{ Lesion site } & \multicolumn{3}{c}{ Lesion size } \\
\cline { 2 - 6 } & Lateral type & In linear & $<\mathbf{2} \mathbf{~ c m}$ & $\mathbf{2 ~} \sim \mathbf{5} \mathbf{~ m ~}$ & $>\mathbf{5} \mathbf{~ c m}$ \\
\hline $\mathrm{N}$ & 62 & 23 & 16 & 59 & 10 \\
$\%$ & 72.94 & 27.06 & 18.82 & 69.41 & 11.77 \\
\hline
\end{tabular}

Table 7. Shows CT/MRI and pathologic comparison.

\begin{tabular}{c|cccc|cc|c}
\hline & \multicolumn{4}{|c|}{ Tumor stage } & \multicolumn{2}{c|}{ Lesion location } & \multirow{2}{*}{ Lymph node involvement } \\
\cline { 2 - 8 } & $\mathbf{1 A}$ & $\mathbf{1 B}$ & $\mathbf{2}$ & $\mathbf{3}$ & in linear & lateral type & 3 \\
CT/MR Results & 2 & 1 & 2 & 3 & 3 & 5 & 2 \\
Pathological findings & 2 & 1 & 3 & 2 & 3 & 5 & 2 \\
\hline
\end{tabular}

in 4 pt. CT diagnosis was consistent with the clinical and pathological report; with coincidence rate of $67 \%(4 / 6)$. 2 patient diagnosed with MR were also consistent with clinical and pathological judgment. 8 patients underwent inguinal lymph node dissection, a total of 42 lymph node resected. Lymph node metastasis in 10 patient size was 6 to $40 \mathrm{~mm}$, median $12 \mathrm{~mm}$; and lymph node metastasis-free in 32 patients; the size was 5 to $12 \mathrm{~mm}$, median $8 \mathrm{~mm}$. The median difference between the two was statistically significance $(P=0.019<0.05)$. CT and MRI tumor stage, tumor location, lymph node involvement and pathologic comparison data as shown in (Table 7).

\section{Clinical stage and lymph node metastasis}

According to 2009 VC FIGO staging criteria, [3] among 85 cases of VC 30 cases of stage I , 41 cases of stage I I, 13 cases of stagel I and 1 case of stage IV as shown in (Table 1 ). Patients with stage I, 4 with stage II, 2 with stage III \& stage IV patient did not underwent surgery. 77 cases of surgical patient with pathologically confirmed tumor and vascular invasion by 1 case. VC surgery patients were 77 in number, preoperative palpable inguinal lymph nodes were 10 (pathologically confirmed), 3 cases of inguinal lymph node metastasis; preoperatively not palpable inguinal lymph nodes were 41 cases of pathologically confirmed inguinal lymph node , 10 cases of metastasis (Figure 3).

\section{Surgical treatment}

In this study, 18 cases of local excision of the genital lesions, including 2 cases of simple resection, 3 were focal resection; another 13 cases of elderly patients aged 71 to 88 years old, accompanied by diabetes, coronary artery disease, hypertension and others. Thus only palliative excision was done. Regarding vulval radical surgery resection was done 


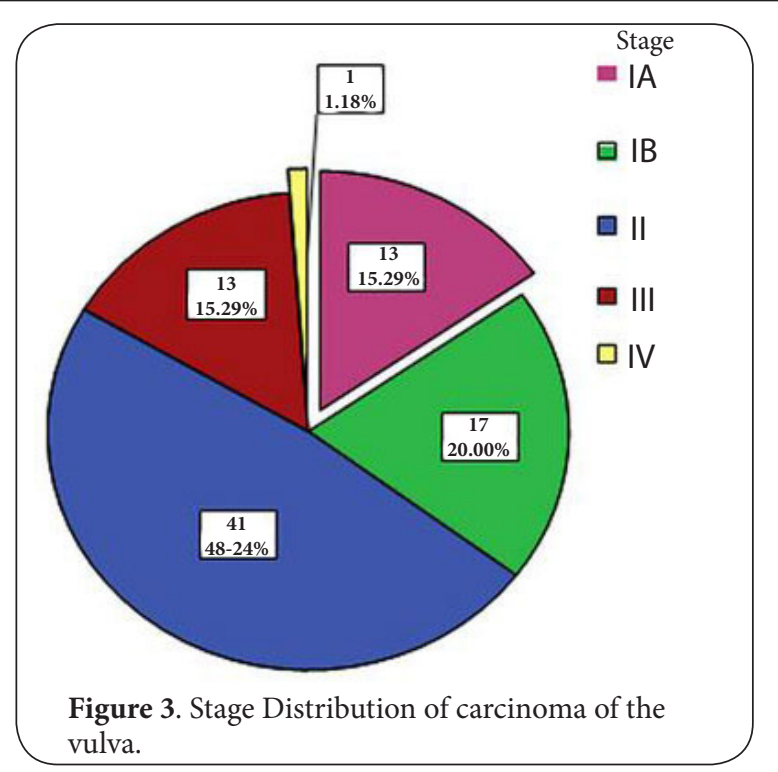

Table 8. Clinical stage of vulvar excision.

\begin{tabular}{|c|c|c|c|c|}
\hline Surgical & I stage & II stage & III stage & Total \\
\hline Local excision of the genital lesions & 5 & 10 & 2 & 17 \\
\hline Some genital radical mastectomy & 2 & 3 & 3 & 8 \\
\hline Extensive vulvectomy & 0 & 1 & 0 & 1 \\
\hline $\begin{array}{l}\text { Partial vulvectomy + bilateral } \\
\text { inguinal lymphadenectomy }\end{array}$ & 16 & 13 & 2 & 31 \\
\hline $\begin{array}{l}\text { Extensive vulvectomy + bilateral } \\
\text { inguinal lymphadenectomy }\end{array}$ & 6 & 10 & 4 & 20 \\
\hline Total & 29 & 37 & 11 & 77 \\
\hline
\end{tabular}

Table 9. Vulvar extensions of surgical resection and recovery (\%).

\begin{tabular}{ccccc}
\hline Surgical & No. of cases & Infection & Wound dehiscence & $\begin{array}{c}\text { Average length } \\
\text { of stay (days) }\end{array}$ \\
\hline I & 17 & $1(5.88)$ & $0(0)$ & 12.18 \\
II & 39 & $14(35.90)$ & $4(10.26)$ & 19.97 \\
III & 21 & $14(66.67)$ & $3(14.29)$ & 41.48 \\
Total & 77 & $29(37.66)$ & $7(9.09)$ & 24.12 \\
X $^{2} /$ F Value & - & 14.889 & 2.450 & 29.308 \\
P Value & - & 0.01 & 0.294 & 0.000 \\
\hline
\end{tabular}

Note: I simply lesion resection; II, part of vulvar radical with or without lymph node dissection; III, extensive vulvectomy with or without lymph node dissection.

with $>2 \mathrm{~cm}$ of the lesion, the surrounding normal skin, subcutaneous normal tissue of the vulva and try to retain the retained urethra and anus. A total of 39 cases, including 8 cases of the untreated lymph node, 1 case underwent bilateral inguinal lymph node dissection. A total of 21 cases, lymph node was not removed in 1 case, in 20 cases both inguinal lymph nodes was removed (Table 8).

\section{Impact of surgery on wound healing}

77 patients underwent surgical procedure, out of which 29 patients had postoperative wound infection or delayed
Table 10. Inguinal lymph node dissection and wound recovery $(\%)$.

\begin{tabular}{ccccc}
\hline Surgical & $\begin{array}{c}\text { The } \\
\text { number of } \\
\text { cases }\end{array}$ & $\begin{array}{c}\text { infection/delayed } \\
\text { healing }\end{array}$ & $\begin{array}{c}\text { Wound } \\
\text { dehiscence }\end{array}$ & $\begin{array}{c}\text { Average length } \\
\text { of stay (days) }\end{array}$ \\
\hline I & 8 & $2(25.00$ & $1(12.5)$ & 15.13 \\
II & 31 & $12(38.71)$ & $3(9.68)$ & 21.23 \\
$\mathrm{X}^{2} / \mathrm{t}$ Value & - & $0.094^{\mathrm{a}}$ & $0.000^{\mathrm{a}}$ & 3.727 \\
$\mathrm{P}$ Value & - & 0.759 & 1.000 & 0.001 \\
\hline
\end{tabular}

Note: I, part of the vulvar radical mastectomy; II, part of vulvar radical + bilateral lymphadenectomy; a continuous correction of the chi-square value, uncorrected $\chi 2$ were $0.519,0.055 \mathrm{P}$ values were $0.417,0.815$

healing, accounting for $37.66 \% .7$ cases of wound dehiscence accounting for $9.09 \%$. There was significant influence in the hospitalization time in extensive vulvectomy with or without lymph node dissection ( $\mathrm{X}=14.889, \mathrm{P}=0.01<0.05$; $F=29.308, P=0.000<0.01$ ), and no significant correlation with incision dehiscence of vulvar resection $(X 2=2.450, P>0.05)$ (Table 9). There was no significant relationship $(P>0.05)$ in patient underwent vulvar resection with lymph node, lesion with wound infection and dehiscence for patient with inguinal node resection, but in patient with inguinal node resection the average hospital stay were prolonged. There is significant influence of lymph node dissection (inguinal) with simple vulvectomy patient in hospital stay $\mathrm{T}=3.727, \mathrm{P}=0.001(0.01)$ (Table 10) .

\section{Pathological conditions}

In 85 cases of VC there were 72 cases of squamous cell carcinoma (72/85) 84.71\%, 5 malignant melanoma (5/85) $5.88 \%, 4$ basal cell carcinoma (4/85) 4.71\%, 3 verrucous carcinoma cell carcinoma (3/85) 3.53\%, and 1 extra mammary Paget's disease (1/85) $1.18 \%$. Squamous cell carcinoma is the main pathological VC type. Out of 72 cases 57 were highly differentiated squamous cell carcinoma (79.17\%), 11 were differentiated $(15.28 \%), 4$ were poorly differentiated ca (5.56\%). Inguinal lymph node resection in 51, and lymph node metastasis were found in 13 cases (25.49\%) (Table 11). Histological grades of squamous cell carcinoma and lymphatic metastasis decreases and increases with the degree of differentiation and lymphnode metastasis respectively ( $\mathrm{X} 2$ $=8.53 \mathrm{P}=0.014<0.05)($ Table 12)

\section{Postoperative complications}

Anemia in $20(25.97 \%)$ cases, wound infection or delayed healing occurred in 29 (37.66\%); 7 wound dehiscence (9.09\%); retention caused by lymphatic cyst 6 (7.79\%), Urethral stricture in 1, 3 deep vein thrombosis(DVT) (3.90\%) and Vaginal stenosis in 3 cases (3.90\%). Major complication of operation of vulva was infection and delayed healing.

\section{Follow-up}

Before 2009 most patients were lost. After 2009 the follow-up to 30 (35.29\%) cases were feasible. Among them 7 pt. with 
Thakur et al. Gynecology 2013,

http://www.hoajonline.com/journals/pdf/2052-6210-1-5.pdf

doi: $10.7243 / 2052-6210-1-5$

Table 11. Histopathological results (\%).

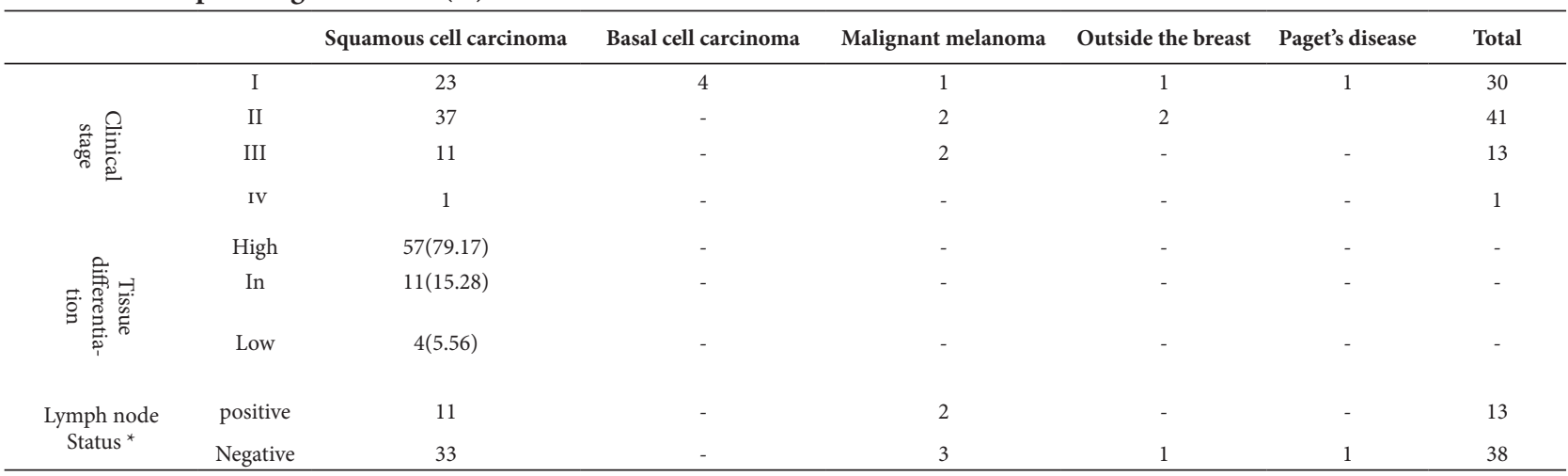

* Lymphadenectomy in 51 cases, 10 patients with pathologically confirmed ipsilateral lymph node metastasis, the pathologically confirmed three cases in linear transferred to bilateral lymph node, lymph node negative patients with lymphatic vascular invasion.

Table 12. histological grade and lymph node status.

\begin{tabular}{lc|c|c|c}
\hline & \multicolumn{2}{|c|}{ Lymph node status } & \multirow{2}{*}{ Total } \\
\cline { 3 - 4 } & Positive & Negative & \\
\hline \multirow{3}{*}{ Histological grade } & Well-differentiated & 5 & 26 & 21 \\
& In differentiation & 4 & 6 & 10 \\
& Poorly differentiated & 2 & 1 & 3 \\
& Total & 11 & 33 & 44 \\
\hline
\end{tabular}

Table 13. Analysis of the vulvar Cancer recurrence.

\begin{tabular}{|c|c|c|c|c|c|c|c|c|c|c|c|}
\hline \multirow{2}{*}{ Surgical } & \multicolumn{3}{|c|}{ Clinical stage } & \multicolumn{3}{|c|}{$\begin{array}{c}\text { Organizational } \\
\text { differentiation }\end{array}$} & \multicolumn{3}{|c|}{ Surgical approach } & \multicolumn{2}{|c|}{ Recurrence site } \\
\hline & I & II & III & High & In & Low & I & II & III & $\begin{array}{l}\text { simply vulvar } \\
\text { recurrence }\end{array}$ & $\begin{array}{l}\text { Lymph node metastasis } \\
\text { and recurrence }\end{array}$ \\
\hline Recurrent cases & 0 & 3 & 4 & 3 & 1 & 1 & 2 & 2 & 3 & 5 & 2 \\
\hline$\%$ & 0 & 42.9 & 57.1 & 60 & 20 & 20 & 38.6 & 28.6 & 42.9 & 71.4 & 28.6 \\
\hline
\end{tabular}

stage I, 14 of stage II, 9 with stage III; out of which there were 28 squamous cell carcinoma, and 2 cases of malignant melanoma. Recurrence in 7(23.33\%) including 2 cases of 73 and 88 -year old underwent radical vulvectomy and inguinal lymph node excision. The other patient was first treated with vulvectomy and inguinal lymphadenectomy. Out of 7 cases 5 of recurrence with squamous cell carcinoma, 2 cases of malignant melanoma. The cases of Squamous cell carcinoma with high median and poor differentiation were 3 , 1 , and 1 respectively. Relapse after treatment was minimum of 2 months and maximum of 3 years. The median time to relapse was 15 months. 5 of 8 patient relapsed with vulvar local recurrence (71.43\%) (Table 13).

\section{Discussion}

Vulvar cancer is one of malignant tumor of the female genital tract. The incidence rate is about 2 to 3 cases/100,000 [1]. Due to HPV infection and obesity its ratio increased rapidly. In future the rate of $\mathrm{VC}$ will continue to rise. The data from the Second Hospital of Jilin University from 1991 to 2010, cases of VC analysis showed same. VC mainly occurred in rural patient but since 1991, the incidence in urban women has also been raised. However the incidence is still higher in rural patient $(56.41 \%)$ than urban (43.59\%). According to previous reports in recent years, there have been significant rising trend of VC in younger age [5]. In this study, the age distribution ranges from 24 to 88 -year-old, with average age $57.09 \pm 12.93$ years old, and with a peak age of 56 to 61 -year-old. The mean age of onset at different period from 2002-2012 was $63.38 \pm$ 10.38 years which dropped in 2010-2012 to $54.33 \pm 14.86$ years. After the statistical analysis, the age of onset of VC declines year by year, this shows consistent ratio with the previously reported literatures. 50 cases with VC were postmenopausal accounting for $58.82 \%$; it's also consistent with the literature [6]. Studies have shown that there is some correlation between white lesion of vulva and progesterone levels. Higher the progesterone levels, higher the risk of white lesions of the vulva while the white vulva is one of the common causes of VC [7]. Studies have shown that HPV infection and VC are closely related to the occurrence of the HPV virus detection rate $(40.4 \%)$, i.e., common type of HPV 16,33 , and 18 [8]. Lichen sclerosis has $4 \%$ to $6 \%$ of the possibility of the 
Thakur et al. Gynecology 2013,

development of VC [9]. In this study obesity, VNED, HPV infection, Hypertension, Diabetes mellitus, and history of genital surgery accounted for 33 cases (38.82\%), 25 cases (29.41\%), 4 cases (12.9\%), 10 cases (11.16\%), 13 cases (15.29\%), and 23 cases $(27.06 \%)$ respectively. By statistical analysis VC occurrence, VNED and HPV infection had no significant correlation with sample size, considering the possibility of fewer and lower rates of HPV screening. High-risk group's patient is recommended to have regular physical examinations to improve the early diagnosis and early treatment. Longterm genital itching is the earliest common symptom in most patients. Other symptoms include genital or genital ulcer, genital or vulvar mass, genital bleeding, dysuria, and pain. On physical examination visible genital lumps or ulcers, may be associated with the surrounding skin hypopigmentation, hyperpigmentation plaques, macules or papules. Data showed that, Genital lesions were located to lateral side i.e., more consistent with the literature. Most of the patient in this study had lesion size between $2 \mathrm{~cm}-5 \mathrm{~cm}$. In recent years, some scholars have pointed out that the vulvar cytology initial screening of malignant lesions of the vulva is reducing unnecessary biopsy. In this study, 85 patients with VC, 78 pt. underwent biopsy; the biopsy rate was $91.76 \%$. The biopsy coincidence rate of $93.58 \%$ (73/78), 5 cases of biopsy and postoperative pathological discrepancies (including 1 case of the vulva melanin cell nevus, malignant melanoma, biopsy diagnosis of localized squamous epithelium was light moderate dysplasia, verrucous squamous cell carcinoma, biopsies extramammary Paget's disease, well-differentiated squamous cell carcinoma, 1 st case diagnosed as genital chronic inflammation, the 2 nd of well-differentiated squamous cell carcinoma); routine colposcopy shows the vulval local vascular in a mosaic, intraoperative rapid pathological diagnosis - poorly differentiated vulvar squamous cell carcinoma. Literature prompted the high specificity of CT examination in the judgment of VC lymph node metastasis therefore has an important applications in the preoperative staging [10]. The presence of CT examination overestimates or underestimates the clinical stage possibility. CT should determine the presence or absence of lymph node metastasis, to be based on the number of lymph nodes and the size of the lymph node [11]. Information found metastasis more overlap between lymph node size, but the difference was statistically significant $(P=0.019)$. Lymph node enlargement shows the highest incidence of lymph node metastasis. Prompted less, no lymph nodes involved preoperative diagnosis of 85 cases of vulvar cancer patients in this study CT in 6 cases, MR 2 cases which is very small sample size. Minimally invasive surgery is the hot spot trends nowadays. On Traditional open laparotomy; it is difficult to dissect inguinal lymph node. It may damage to large internal organs, incision healing difficulties and others postoperative complication. While of lapraroscopic inguinal lymph node dissection, minor trauma may occur, hospital stay is shortength, and faster wound healing are the best prospects. Postoperative incision infection of valvular resection had significant influence on hospitalization time $(X 2=14.889, P=0.01<0.05 ; F=29.308$, $P=0.000<0.01)$. Therefore, treatment of vulvar lesion should be according to the stage. At the early stage of $\mathrm{VC}$ it may be appropriate to reduce the scope of operation, $2 \mathrm{~cm}-3 \mathrm{~cm}$ above the cutting edge, and operation of properly preserved subcutaneous tissue thickness, can increase blood circulation, and relieve tension incision healing to promote the incision. Routine preservation of the sapheneous vein during inguinal lymph node resection for VC significantly can shorten the operative time, reduce the lymphatic vessels and peripheral nerve injury, and incidence of hematoma [12]. VC patient using the implementation of the inguinal lymph node dissection do not make patients benefit, but can increase the incisional infection, dehiscence and chronic lymphatic swelling and other postoperative complications. Hampl on routine SLN biopsy in 127 patients with T1-T3, VC in 125 patients, 36 of 39 cases dissected lymph node-positive patients with positive SLN biopsy, a sensitivity of $92.3 \%$ [13]. 3 false negative SLN patients (7.7\%) are located in the midline of the primary tumor. Ultra installments negative predictive value of sentinel lymph node biopsy (NPV) from $97 \%$ to $100 \%$ Studies have shown that less than $4 \mathrm{~cm}, \mathrm{~T} 1$ or T2, infiltration depth of less than $1 \mathrm{~mm}$ of vulvar squamous cell carcinoma were treated with sentinel lymph node biopsy has better security and accuracy [14-15]. Information has not yet been adopted sentinel lymph node biopsy technique therefore should improve preoperative lymph node biopsy technique. Early VC sentinel lymph node biopsy shows: 1) pathology screening micrometastasis, there are still some difficulties need to develop such as tissue microarray technology, has higher sensitivity. Combination of molecular biology techniques such as RT-PCR detection of sentinel lymph node does not yet have clinical utility [16]. De Hutu suggests that the use of the methilyn blue assay SLN sensitivity of only $60 \%$, hematoxylin-eosin staining sensitivity of $80 \%$. Combined with immunohistochemical techniques for tumor antigens can be detected by the presence of micrometastasis, to achieve tumor "super stage" [17]. The incidence of genital extramammary Paget's disease in this study is consistent with the literature [18]. The disease lesions confined to the epidermis had better prognosis [19]. In research it is still controversial about the margin on the pathological type of operation. Black et al., [20] considered the pathological positive margins leading to post-operative recurrence rate were significantly higher (70\% and $38 \%)$. In this study patients surgically treated was pathologically confirmed as negative margins. In VC malignant degree of differentiation pathological type differs prognostic factors and treatment are also different. Therefore, tumor biopsy before treatment is still an important method to guide the diagnosis and follow up treatment. The exudation from the incisional operated wound, there are chances of skin infection, cellulitis and formation of lymphatic cyst. 
Thakur et al. Gynecology 2013,

http://www.hoajonline.com/journals/pdf/2052-6210-1-5.pdf

doi: $10.7243 / 2052-6210-1-5$

Therefore to prevent the oozing of blood it is essential to have the proper dressing and drainage of the wound to prevent wound infection and promote wound healing. Often with the 24 hours $1-1.5 \mathrm{~kg}$ weight compression is given to the patient with indwelling drainage tube, should maintain the negative pressure suction for 4-6 days. The negative pressure can be maintained at about $0.98 \mathrm{kPa}$. Drainage bag should be changed daily. The main prediction factors for locally recurrent valvular cancer are 1) operating margin of tumor is near or close, 2) the depth of tumor invasion $>5 \mathrm{~mm}, 3$ ) lymphatic vessel invasion and tumor infiltration growth pattern. The main predictors of groin, pelvis and distant recurrence factors are the numbers of lymph node metastasis and tumor differentiation or histopathological grade [21]. We should strengthen the patient awareness regarding the disease and its outcome. Establish the appropriate follow up file tracing control on the therapeutic effect of disease so as to improve the level of diagnosis and treatment.

\section{Conclusions}

Cases of VC in young patient increasing every year. The VC ratio between the urban and rural areas is found to be more in urban patients than rural patients. Incidence of VC was seen in those patients who had hypertension, obesity and diabetes mellitus. Aggressive treatment of high-risk groups should be the primary concern, regular examination is recommended. Symptom such as long term vulvar itching, genital warts, genital ulcers may increase the possibility of VC. Preoperative colposcopy and biopsy can improve the accuracy of early diagnosis. The application of CT and MRI in the preoperative diagnosis should be strengthen. Postoperative complications were mainly wound infection. The follow up rate is low, so it is difficult to analyze the related factors of recurrence and calculate the survival rate in years. With these entire datas prognosis cannot be predicted.

\section{Competing interests}

The authors declare that they have no competing interests.

\section{Authors' contributions}

Zheng Guiying was the coordinator of the study. R Thakur

designed the study and carried out most of the study. All coauthor collected the clinical information and provided

valuable suggestions in the preparation of the manuscript.

\section{Acknowledgement}

The authors would like to thank Bhojraj Sharma, and

Punyaram Kharbuja for help with manuscript preparation.

Publication history

Received: 08-May-2013 Accepted: 20-May-2013

Published: 24-May-2013

\section{References}

1. Woelber L, Kock L, Gieseking F, Petersen C, Trillsch F, Choschzick $\mathrm{M}$, Jaenicke $\mathrm{F}$ and Mahner S: Clinical management of primary vulvar cancer. Eur J Cancer 2011, 47:2315-21. | Article | PubMed

2. Gillison ML, Chaturvedi AK and Lowy DR: HPV prophylactic vaccines and the potential prevention of noncervical cancers in both men and women. Cancer 2008, 113:3036-46. | Article I PubMed

3. Pecorelli S: Revised FIGO staging for carcinoma of the vulva, cervix, and endometrium. Int J Gynaecol Obstet 2009, 105:1034. | Article | PubMed

4. Richard SD, Krivak TC, Beriwal S and Zorn KK: Recurrent metastatic vulvar carcinoma treated with cisplatin plus cetuximab. Int J Gynecol Cancer 2008, 18:1132-5. | Article | PubMed

5. Hampl M, Sarajuuri H, Wentzensen N, Bender HG and Kueppers $\checkmark$ : Effect of human papillomavirus vaccines on vulvar, vaginal, and anal intraepithelial lesions and vulvar cancer. Obstet Gynecol 2006, 108:1361-8. | Article | PubMed

6. Kara M, Colgecen E, Yildirim EN: Vulvar basal cell carcinoma. Indian J Pathol Microbiol 2012, 55:583-4. I Article

7. Rebonato A, D'Andrea A, Scialpi M: Painless but problematic. Imaging modalities were useful in the diagnosis and treatment of an unusual tumor. Am J Obstet Gynecol 2013, 208:237.e1-2. Article

8. Smith JS, Backes DM, Hoots BE, Kurman RJ and Pimenta JM: Human papillomavirus type-distribution in vulvar and vaginal cancers and their associated precursors. Obstet Gynecol 2009, 113:917-24. | Article | PubMed

9. Funaro D: Lichen sclerosus: a review and practical approach. Dermatol Ther 2004, 17:28-37. | Article | PubMed

10. Michel Prefontaine, Helen Ettler, Dominique Lanvin, Monique Bertrand, Jean-Luc Urbain and Tarik Belhocine Added-value of SPECT/CT in patients undergoing LM/SL for gynecological cancers J Nucl Med. 2009; 50 (Supplement 2):1701.

11. McMahon CJ, Rofsky NM and Pedrosa I: Lymphatic metastases from pelvic tumors: anatomic classification, characterization, and staging. Radiology 2010, 254:31-46. | Article I PubMed

12. Dardarian TS, Gray HJ, Morgan MA, Rubin SC and Randall TC: Saphenous vein sparing during inguinal lymphadenectomy to reduce morbidity in patients with vulvar carcinoma. Gynecol Oncol 2006, 101:140-2. | Article | PubMed

13. Hampl M, Hantschmann P, Michels W and Hillemanns P: Validation of the accuracy of the sentinel lymph node procedure in patients with vulvar cancer: results of a multicenter study in Germany. Gynecol Oncol 2008, 111:282-8. | Article | PubMed

14. Levenback CF: How safe is sentinel lymph node biopsy in patients with vulvar cancer? J Clin Oncol 2008, 26:828-9. I Article I PubMed

15. Vidal-Sicart S, Puig-Tintore LM, Lejarcegui JA, Paredes $P$, Ortega ML, Munoz A, Ordi J, Fuste P, Ortin J, Duch J, Martin F and Pons F: Validation and application of the sentinel lymph node concept in malignant vulvar tumours. Eur J Nucl Med Mol Imaging 2007, 34:384-91. | Article | PubMed

16. Rutgers EJ: Sentinel node biopsy: interpretation and management of patients with immunohistochemistry-positive sentinel nodes and those with micrometastases. J Clin Oncol 2008, 26:698-702. | Article | PubMed

17. Lupi G, Raspagliesi F, Zucali R, Fontanelli R, Paladini D, Kenda $\mathrm{R}$ and di Re F: Combined preoperative chemoradiotherapy followed by radical surgery in locally advanced vulvar carcinoma. A pilot study. Cancer 1996, 77:1472-8. | Article | PubMed

18. Tebes S, Cardosi R and Hoffman M: Paget's disease of the vulva. Am J Obstet Gynecol 2002, 187:281-3; discussion 283-4. | 
Thakur et al. Gynecology 2013,

http://www.hoajonline.com/journals/pdf/2052-6210-1-5.pdf

doi: $10.7243 / 2052-6210-1-5$

Article I PubMed

19. Jones IS, Crandon A and Sanday K: Paget's disease of the vulva: Diagnosis and follow-up key to management; a retrospective study of $\mathbf{5 0}$ cases from Queensland. Gynecol Oncol 2011, 122:42-4. | Article | PubMed

20. Black D, Tornos C, Soslow RA, Awtrey CS, Barakat RR and Chi DS: The outcomes of patients with positive margins after excision for intraepithelial Paget's disease of the vulva. Gynecol Oncol 2007, 104:547-50. | Article | PubMed

21. Maggino T, Landoni F, Sartori E, Zola P, Gadducci A, Alessi C, Solda M, Coscio S, Spinetti G, Maneo A, Ferrero A and Konishi De Toffoli G: Patterns of recurrence in patients with squamous cell carcinoma of the vulva. A multicenter CTF Study. Cancer 2000, 89:116-22. | Article | PubMed

\section{Citation:}

Thakur R, Nijamudin, Xue hua Z, Mengli Z, yan Jun W, Yuan T and Guiying Z: Clinical analysis of vulvar carcinoma. Gynecology 2013, 1:5.

http://dx.doi.org/10.7243/2052-6210-1-5 